\title{
Early Monitoring of Infliximab Serum Trough Levels Predicts Long-Term Therapy Failure in Patients With Axial Spondyloarthritis
}

Ana Martínez Feito ( $\square$ amartinezf@salud.madrid.org )

Hospital La Paz Institute for Health Research https://orcid.org/0000-0002-5580-8387

Victoria Navarro-Compán

Hospital Universitario La Paz

Borja Hernández-Breijo

Fundacion Investigacion Biomedica Del Hospital Universitario La Paz

Eva Olariaga-Mérida

Fundacion Investigacion Biomedica Del Hospital Universitario La Paz

Diana Peiteado

Hospital Universitario La Paz

Alejandro Villalba

Hospital Universitario La Paz

Laura Nuño

Hospital Universitario La Paz

Irene Monjo

Hospital Universitario La Paz

Cristina Diego

Hospital Universitario La Paz

Dora Pascual-Salcedo

Fundacion Investigacion Biomedica Del Hospital Universitario La Paz

Pilar Nozal

Hospital Universitario La Paz

Alejandro Balsa

Hospital Universitario La Paz

Chamaida Plasencia-Rodriguez

Hospital Universitario La Paz

Research article

Keywords: axial spondyloarthritis; infliximab, cut-off, long term, non-clinical response. 
Posted Date: August 6th, 2020

DOl: https://doi.org/10.21203/rs.3.rs-53265/v1

License: (c) (i) This work is licensed under a Creative Commons Attribution 4.0 International License. Read Full License 


\section{Abstract}

Background: The aim of our study is to evaluate whether serum infliximab trough levels (ITL) during the early stages of treatment are predictive of long-term clinical failure in patients with axial spondyloarthritis (axSpA).

Methods: Longitudinal observational study involving 81 patients with axSpA recruited from the SpA-Paz cohort and monitored during infliximab therapy. Serum ITL were measured at baseline, week 2 (W2), W6 and W12 of treatment. Disease activity was assessed by the Ankylosing Spondylitis Disease Activity Score (ASDAS) at baseline, W24 and W54, and every 6 months thereafter until therapy failure. Nonclinically important improvement was defined by $\triangle$ ASDAS $<1.1$. The association between serum ITL levels at W12 and clinical outcomes (non-improvement at W52, drug survival and drop-out due to secondary inefficacy) was investigated through logistic regression models and Kaplan Meier curves. Receiver operating characteristic (ROC) curves were employed to determine the best cut-off for serum ITL.

Results: Out of the 81 patients, 45 (56\%) did not achieve clinical improvement at W52. These patients had lower serum ITL at W12 compared to those who improved: ITL [median (IQR)]: 4.1(0.9-8.3) $\mu \mathrm{g} / \mathrm{ml}$ vs 7.1(4.3-11.3) $\mu \mathrm{g} / \mathrm{ml}$, respectively; $p=0.007)$. A cut-off of $I T L<6.7 \mu \mathrm{g} / \mathrm{mL}$ at $W 12$ was significantly associated with: i) not achieving clinical improvement at W52 (OR: 2.3; 95\%Cl: 1.3-3.9); ii) shorter drug survival (5.0 years (95\% Cl: $3.8-6.2)$ vs 7.6 years (95\% Cl: $4.8-6.9) ; \mathrm{p}=0.04)$; and iii) higher drop-out rates due to secondary inefficacy (OR: $3.5 ; 95 \% \mathrm{Cl}: 1.2-10.2)$.

Conclusions: Serum ITL $<6.7 \mu \mathrm{g} / \mathrm{mL}$ at W12 were associated with long-term clinical failure in patients with axSpA, especially due to secondary inefficacy.

\section{Introduction}

In axial spondyloarthritis (axSpA), tumor necrosis inhibitors (TNFi) have been shown to be effective for improving signs and symptoms in cases of persistently high disease activity (1). Accordingly, TNFi are recommended as the first biological therapy for patients with axSpA. In such cases, infliximab (Ifx), a chimeric TNFi, is widely used in clinical practice. However, data from clinical registries have shown that after 2 years of treatment up to $30-45 \%$ of patients experience therapy interruption, clinical inefficacy being the main reason for discontinuation $(2,3)$. Out of these patients, $19-23 \%$ experience lack of efficacy from the very beginning of treatment, while the rest initially respond to infliximab but then somehow lose this response over time.

TNFi must be available in a sufficient quantities to achieve their effects and a concentration-dependent effect has been described (4). Most of the good clinical responders present significantly higher serum concentrations than non- and moderate responders during the first year of treatment $(5,6)$, although a wide variation in pharmacokinetics has been described (7-9). 
Several variables may affect pharmacokinetics-pharmacodynamics of Ifx and the clinical response of patients to this drug. These include the degree of disease activity (inflammatory burden), the development of anti-drug antibodies (ADA), the concomitant use of conventional synthetic diseasemodifying anti-rheumatic drugs (csDMARDs) and patient-related characteristics such as body-mass index (BMI) (10). As high disease activity is associated with higher concentrations of TNF-a in both swollen tissue and serum, such patients require greater amounts of drug to neutralize TNF-a. This situation is known as an "inflammatory sink" $(10,11)$ and results in lower serum drug concentrations; lower available drug levels, results in an inverse correlation between baseline disease activity and serum TNFi levels.

In addition, the development of immunogenicity increases drug clearance and is associated with low serum drug levels and consequently with lack of response (12). The concomitant use of csDMARDs like methotrexate (MTX) is also associated with the presence of serum drug, in part due the prevention of ADA formation (13-15). ASAS-EULAR advises against using csDMARDs to control axial disease in patients with axSpA (1); however, in clinical practice, csDMARDs are used for treating peripheral joint or extra-musculoskeletal manifestations (13) .

With the onset of new biological therapies directed to such cytokines as IL-17, early prediction of TNFi failure remains one of the main unmet goals in patients with axSpA. Monitoring serum drug concentrations during the early stages of treatment could be a feasible approach for predicting nonresponse to biologicals. In this regard, determining a serum drug concentration that best correlates with clinical results has been the principal aim of several studies carried out in other inflammatory diseases $(5$, $6,16-18)$. However, there is scant data about the value of Ifx levels for this purpose in axSpA patients (19).

The aim of the present work was to study whether serum Ifx trough levels (ITL) during the early stages of the treatment (within the first 12 weeks) could help predict long-term clinical failure to the TNFi Ifx in patients with axSpA.

\section{Methods}

\section{Study design and patients}

This longitudinal, observational study included patients with axSpA recruited from the SpA-Paz cohort (8). This is an ongoing cohort started in 2006 (8) and prospectively includes all patients with axSpA initiating biological therapy at the Rheumatology Department of La Paz University Hospital (Madrid). In addition, since 2010, serum samples have been collected to measure serum drug levels and the presence of $A D A$.

All included patients were diagnosed with axSpA by their treating physician and began Ifx therapy in accordance with national guidelines (20). Patients received intravenous infusions of Ifx (5 mg/kg) at 
week (W) 0, 2 and 6 and every 8 weeks thereafter. Serum samples were collected at baseline and immediately before each infusion.

The study was approved by the Medical Ethics Committee of La Paz University Hospital (PI-1155) and all patients provided signed informed consent.

\section{Clinical disease activity and treatment response}

Disease activity was assessed by the Ankylosing Spondylitis Disease Activity Score using C-reactive protein (CRP-ASDAS) at baseline, W24 and W52. Non-clinically important improvement was defined by $\triangle$ ASDAS value $<1.1$ and clinically important improvement by $\triangle$ ASDAS $\geq 1.1$ (21). In addition, long-term clinical failure was assessed by drug survival and the development of secondary inefficacy (patients who lost clinical improvement after 6 months of therapy).

\section{Measurement of serum Ifx trough levels (ITL)}

Serum ITL were measured by a capture enzyme-linked immunosorbent assay (ELISA) as has been previously described. Serum ITL $>10 \mathrm{ng} / \mathrm{mL}$ were considered positive (22). In total, 304 serum samples were analysed. Serum samples were available from all patients at baseline, at W2 in 72, at W6 in 74 and at W12 in 77 patients .

\section{Statistical analysis}

Descriptive statistics are reported as median and interquartile ranges (IQR), mean and standard deviations (SD) or as absolute numbers and relative frequencies depending on normal distributions. First, the association between serum Ifx levels at the different time points (W2, W6 and W12) and $\triangle$ ASDAS at W24 and W52 was assessed using the Mann-Whitney U test. For this purpose, patients were classified into two groups according to the degree to which they achieved clinically important improvement $(\triangle A S D A S \geq 1.1)$-R- or not ( $\triangle$ ASDAS $<1.1$ )-non-R-. In case of drop-out or missing data before W52, the last observation carried forward (LOCF) was performed. Second, serum-dependent receiver operating characteristic (ROC) curves were used to determine the serum ITL cut-off point that best predicted treatment failure $(\triangle \mathrm{ASDAS}<1.1)$. The sensitivity and specificity of the serum ITL cut-off points were compared in order to select the best cut-off for predicting clinical failure. Third, univariable and multivariable logistic regression models were employed to investigate this association. To this end, the identified cut-off serum ITL at W12, age, sex, HLA-B27, MTX, sulfasalazine (SSZ), BMI, smoking status, prednisone and ASDAS at baseline were included as independent variables in the univariable analyses. The variables with significant associations $(p<0.1)$ in the univariable analysis were included as independent variables in the multivariable analyses. Finally, survival throughout Ifx therapy (median of 3 years) according to the predictive ITL cut-off was studied using Kaplan-Meier curves.

All analysis were performed with GraphPad Prism 6 (San Diego, CA, USA) and SPSS 21.0 software; significant $p$-value $<0.05$. 


\section{Baseline demographics and clinical data.}

Eighty-one consecutive patients with axSpA starting Ifx therapy were included. All patients had predominant axial involvement and $64(79 \%)$ also presented some peripheral (enthesitis, arthritis, dactylitis) or extra-musculoskeletal involvement (uveitis, psoriasis, inflammatory bowel disease). Baseline demographic and clinical characteristics are shown in Table 1. Median (RIQ) age was 45 (37.5-53) years, $55 \%$ were men, and $22 \%$ currently smokers. 
Table 1

Baseline characteristics of patients with axial spondyloarthritis (axSpA) (total population, non-responders and responders)

\begin{tabular}{|c|c|c|c|c|}
\hline Characteristics & $\begin{array}{l}\text { Total } \\
\text { population } \\
(n=81)\end{array}$ & $\begin{array}{l}\triangle \text { ASDAS }< \\
1.1 \\
(n=45)\end{array}$ & $\begin{array}{l}\triangle \text { ASDAS } \geq \\
1.1 \\
(n=36)\end{array}$ & $\begin{array}{l}\mathrm{p} \\
\text { value }\end{array}$ \\
\hline Age, years* & $\begin{array}{l}45(37.5- \\
53)\end{array}$ & $43(37-53)$ & $\begin{array}{l}46.5(38- \\
54)\end{array}$ & 0.5 \\
\hline Body mass index* & $\begin{array}{l}26.6(24.4- \\
29.7)\end{array}$ & $\begin{array}{l}27.8(24.5- \\
29.5)\end{array}$ & $\begin{array}{l}25.6(23.1- \\
30.5)\end{array}$ & 0.5 \\
\hline Male, $n(\%)$ & $48(55 \%)$ & $21(47 \%)$ & $24(67 \%)$ & 0.2 \\
\hline Disease duration, years* & $8.3(4-17.1)$ & $\begin{array}{l}7.3(3.3- \\
12.5)\end{array}$ & $\begin{array}{l}8.4(5.5- \\
19.8)\end{array}$ & 0.07 \\
\hline HLA-B27 positive, n (\%) & $43 / 70(61 \%)$ & $19 / 36(53 \%)$ & 24/34(71\%) & 0.1 \\
\hline Smoking status, n (\%) & & & & 0.2 \\
\hline - Currently smoker & $18(22 \%)$ & $12(28 \%)$ & $6(50 \%)$ & \\
\hline - Non-smoker & $47(58 \%)$ & $24(56 \%)$ & $23(61 \%)$ & \\
\hline - Ex-smoker & $14(17 \%)$ & $5(12 \%)$ & $9(24 \%)$ & \\
\hline Subtype of SpA, n (\%) & & & & 0.3 \\
\hline - Ankylosing Spondylitis & $42(52 \%)$ & $18(42 \%)$ & $24(63 \%)$ & \\
\hline - Undifferentiated SpA & $30(37 \%)$ & $20(47 \%)$ & $10(26 \%)$ & \\
\hline - Psoriatic SpA & $3(4 \%)$ & $2(5 \%)$ & $1(3 \%)$ & \\
\hline $\begin{array}{l}\text { - Spondyloarthropathy with inflammatory } \\
\text { bowel disease }\end{array}$ & $6(7 \%)$ & $3(7 \%)$ & $3(8 \%)$ & \\
\hline ASDAS ** & $3.5(1)$ & $3.1(0.9)$ & $3.8(1)$ & $\dot{0.001}$ \\
\hline BASDAI ** & $6(2)$ & $5.7(2)$ & $6.2(2)$ & 0.27 \\
\hline CRP levels * & $7.6(3-25.7)$ & $\begin{array}{l}4.2(2.1- \\
10.3)\end{array}$ & $\begin{array}{l}16.3(5.5- \\
31.5)\end{array}$ & 0.001 \\
\hline Monotherapy, n (\%) & $35(43 \%)$ & $20(44 \%)$ & $15(42 \%)$ & 0.17 \\
\hline \multicolumn{5}{|l|}{ Concomitant treatment: } \\
\hline Methotrexate, n (\%) & $27(33 \%)$ & $12(27 \%)$ & $15(47 \%)$ & 0.01 \\
\hline
\end{tabular}




\begin{tabular}{|c|c|c|c|c|}
\hline Characteristics & $\begin{array}{l}\text { Total } \\
\text { population } \\
(\mathrm{n}=\mathbf{8 1})\end{array}$ & $\begin{array}{l}\triangle A S D A S< \\
1.1 \\
(n=45)\end{array}$ & $\begin{array}{l}\triangle \text { ASDAS } \geq \\
1.1 \\
(n=36)\end{array}$ & $\begin{array}{l}p \\
\text { value }\end{array}$ \\
\hline Others csDMARDs, $n$ (\%) & 32 (39\%) & $17(38 \%)$ & $15(42 \%)$ & 0.3 \\
\hline Prednisone, n (\%) & $15(19 \%)$ & $7(16 \%)$ & $8(22 \%)$ & 0.08 \\
\hline
\end{tabular}

At W52, 45 (56\%) patients were classified in the group of non-R and 36 (44\%) were classified as R. Globally, 41 (51\%) patients dropped-out the Ifx therapy during follow-up (Median, IQR: 3, 1.3-5.9 years).

Baseline ASDAS were significantly lower in patients who did not achieve clinically important improvement [(mean $\pm S D)$ [3.9(1) in the R-group vs 3.1(0.9) in the non-R-group, $p<0.001]$, as well as CRP levels (median and IQR) [16.3 (5.5-31.5) in the R-group vs $4.2(2.2-10.3)$ in the non-R-group, $p=0.001]]$. Twenty-seven (33\%) patients received concomitant MTX because of extra-axial manifestations, 18 (47\%) in the R group and $9(21 \%)$ in the non-R group; $p=0.01$. None of the other baseline variables was significantly associated with clinical improvement (Table 1).

\section{Association between early serum ITL and baseline variables with non-clinical improvement at week 52.}

Figure 1 shows serum ITL values at W2, 6 and 12 in non-R and R groups. At all studied-time points values in the non R-group were lower compared to the R group: at W2 [37.6 (22-50.8) $\mu \mathrm{g} / \mathrm{ml}$ vs $38.9(27-52)$ $\mu \mathrm{g} / \mathrm{ml} ; \mathrm{p}=0.7]$ and $\mathrm{W} 6[18.7(12.6-26.6) \mu \mathrm{g} / \mathrm{ml}$ vs $24.2(13.6-34.6) \mu \mathrm{g} / \mathrm{ml} ; \mathrm{p}=0.2]$, although only at W12 did they were statistically different $[4.1(0.9-8.3) \mu \mathrm{g} / \mathrm{ml}$ vs $7.1(4.3-11.3) \mu \mathrm{g} / \mathrm{ml} ; \mathrm{p}=0.007]$.

An ROC curve for not achieving clinically important improvement at W52, as defined by $\triangle A S D A S<1.1$, was calculated in relation to the serum ITL at W12 (Fig. 2). The area under the curve (AUC) was 0.678 (95\% confidence interval $(\mathrm{CI}): 0.558-0.797), p=0.007)$. The cut-off value chosen to discriminate between non-R and R (with a sensitivity of $55 \%$, specificity of $70 \%$, PPV of $63 \%$ and NPV of $64 \%$ ) was at Ifx serum trough concentrations of $6.7 \mu \mathrm{g} / \mathrm{mL}$. Out of the 77 patients with available serum samples at W12, 45 (58\%) had serum ITL below the threshold and $32(42 \%)$ above it. Most patients in the non-R group had serum ITL $<6.7 \mu \mathrm{g} / \mathrm{ml}(29 / 41$ (71\%) below vs 12/41 (29\%) above; $\mathrm{p}=0.02)$ (Fig. 3).

In the univariable analysis, two variables were significantly associated with not achieving clinically important improvement at W52: serum ITL below $6.7 \mu \mathrm{g} / \mathrm{ml}$ at W12 (OR: 3.0; 95\% Cl: 1.2-7.7) and lower baseline ASDAS (OR: $2.4 ; 95 \% \mathrm{Cl}: 1.4-4.0$ ). In the multivariable analysis, both variables, serum Ifx levels < $6.7 \mu \mathrm{g} / \mathrm{mL}$ at W12 (OR: 3.8; 95\%Cl: 1.3-11.2) and lower baseline ASDAS (OR: 2.3; 95\%Cl: 1.3-3.9) remained significantly associated with the non-clinically important improvement at W52. 


\section{Predictive value of early serum ITL (W12) to predict drug survival and secondary inefficacy over long-term follow up.}

Mean survival time on the treatment was significantly shorter in patients with ITL $<6.7 \mu \mathrm{g} / \mathrm{mL}$ at W12, compared to those with levels above this cut-off: 5.0 years ( $95 \%$ Cl: $3.8-6.2)$ vs 7.6 years (95\% Cl: $4.8-$ 6.9); $p=0.04$ (Fig. 4).

To evaluate the association between ITL at W12 and the predictive accuracy of secondary inefficacy, we performed an analysis in which those patients who dropped-out $(n=6)$ before 52 weeks of treatment were excluded. There were no differences between this cohort $(n=75)$ and the original cohort with 81 patients in terms of both clinical and demographic baseline characteristics (data not shown). Out of 75 axSpA patients, 28 (37\%) developed secondary inefficacy and 7 (17\%) dropped-out due to other reasons (adverse effects, loss of follow-up etc). The median (IQR) time under Ifx therapy of 28 patients with secondary inefficacy was 2.1(1.4-4.8) years and the median for patients who dropped-out for other reasons $(n=8)$ was $2.4(0.7-4)$. The logistic regression analysis showed that Ifx concentrations below the cut-off at W12 (OR: 3.5; 95\%Cl: 1.2-10.2), but lacking baseline ASDAS (OR: 0.9; 95\% Cl: 0.5-1.5), were statistically associated with dropping out of treatment due to secondary inefficacy.

In addition, most of the patients who dropped-out due to secondary inefficacy had Ifx concentrations < $6.7 \mu \mathrm{g} / \mathrm{mL}$ at W12: 19/26(73\%) with ITL, while only $7 / 26(27 \%)$ had at an ITL above the cut off at W12; $p$ $=0.01$ (Fig. 5).

\section{Discussion}

In this study we have shown an association between serum ITL during early stages of the treatment (at week 12) and long-term clinical failure to Ifx, based on non- clinically important improvement at week 52 , drug survival and drop-out due to secondary inefficacy in patients with axSpA. In addition, we defined an ITL cut-off at W12 as predictive of long-term clinical failure in patients with axSpA treated with Ifx.

Some publications highlight the unmet need of identifying predictive factors of clinical response to TNFi, pointing to the role played by serum TNFi levels in this context $(16,17,23,24)$. Most published studies have involved patients with rheumatoid arthritis (RA) treated with infliximab or adalimumab $(16,23,24)$. These studies report that serum drug levels during the first three months of therapy can help to predict patient response to treatment. One study conducted in patients with ulcerative colitis observed that Ifx levels at W2 are useful for predicting short- and long-term outcomes (17). Only one previous work correlated serum ITL levels during the early stages with the onset of immunogenicity, albeit without clinical outcomes in patients with SpA (17). The present study is the first demonstrating that lower serum ITL 3 months after starting therapy are associated with worse clinical outcomes in long-term follow-up in patients with axSpA. 
Moreover, efforts have been focused on identifying a cut-off point for serum drug levels during the early stages to predict clinical outcomes. The majority of studies involved patients with RA $(16,19,25)$ or with inflammatory bowel disease (17). Ducoreau et al. (19) found that trough ITL $>6.5 \mathrm{mg} / \mathrm{L}$ in patients with $\mathrm{SpA}$ at week 12 were associated with longer Ifx survival; however, no clinical outcomes were investigated with this cut-off value. In our axSpA cohort, serum ITL $<6.7 \mu \mathrm{g} / \mathrm{mL}$ at W12 were associated with three clinical outcomes: diminished clinical improvement during the first year of therapy, a higher frequency of dropping out due to secondary inefficacy, and shorter survival time on the treatment.

We observed that lower baseline ASDAS and CRP levels were associated with a lower probability of achieving a clinically important improvement as measured by ASDAS. These findings are consistent with data previously published in patients with SpA, where higher baseline ASDAS and CRP values were found to be associated with a better response to TNFi (26-29). One possible explanation could be that high ASDAS and CRP values at baseline reflect the high proinflammatory burden produced by inflammatory cytokines such as TNFa and IL-6; thus, patients may benefit more from TNFi therapy.

Many predictors have been associated with TNFi survival in axSpA. Female sex, steroid use and persistently high inflammatory levels are found to be negative predictors of treatment response (30). One the other hand, the use of concomitant csDMARDs has been linked to better drug survival (31). However, there is little data correlating serum ITL as a predictor of drug survival. In our study, we shown that $6.7 \mu \mathrm{g} / \mathrm{mL}$ ITL levels at W12 were associated with shorter drug survival time and a 3.5-fold greater probability of dropping-out due to secondary inefficacy than in patients with higher ITL levels.

The main limitation of our study is the relative low number of patients $(n=81)$ and the unavailability of all serum samples throughout all the studied time points. The studied cohort included SpA patients comprising all entities of SpA with axial involvement, in which clinical disease activity and clinical improvement were assessed by ASDAS, as is recommended in axSpA patients (32). This cohort represents standard clinical practice in our hospital.

\section{Conclusions}

In conclusion, lower serum Ifx levels during the early stages (W12) of treatment are associated with longterm clinical failure (W52) in patients with axSpA treated with Ifx. Moreover, Ifx concentrations below $6.7 \mu \mathrm{g} / \mathrm{mL}$ at W12 are associated with shorter drug survival time and a higher proportion of patients who dropped-out due to secondary inefficacy. However, further long-term studies are required to validate the present results.

\section{Abbreviations}

ADA: anti-drug antibodies; ASDAS: Ankylosing Spondylitis Disease Activity Score; axSpA: axial spondyloarthritis; Index; BMI: body mass index; Cl: confidence interval; CRP: C reactive protein; csDMARD: conventional synthetic disease-modifying anti-rheumatic drug; ELISA: enzyme-linked immunosorbent 
assay; HLA-B27: human leucocyte antigen B27; Ifx: infliximab; ITL: infliximab trough level; IQR: interquartile ranges; LOCF: last observation carried forward; MTX: methotrexate; OR: odds-ratio; R: responder; RA: rheumatoid arthritis; ROC: Receiver operating characteristic; SD:standard deviation; SSZ: sulfasalazine; TNF: tumour necrosis factor; TNFi: TNF inhibitor; W: week.

\section{Declarations}

\section{Ethics approval and consent to participate}

The study was conducted according to the guidelines of the 1975 Declaration of Helsinki. Approval was obtained from the Institutional Ethics Committee from the participant Institutions (La Paz University Hospital).

\section{Consent for publication}

All authors have read and approved the manuscript for publication.

\section{Availability of data and material}

All data generated or analysed during this study are included in this published article.

\section{Competing interests}

CP-R has received research grants/honoraria from AbbVie, Lilly, Novartis, Pfizer,Sanofi, Biogen and UCB. VN-C has received research grants/honoraria from AbbVie, Janssen, Lilly, Novartis, Pfizer, and UCB; DP-S has received speaking fees of Abbvie, Pfizer, Takeda, Menarini and Grifols. IM reports personal fees from Roche. AB has received grants and personal fees from Abbvie, Pfizer, Novartis, Roche. Personal fees from Amgen, Sandoz, Lilly, UCB. Personal fees and non- financial support from BMS. Grants, personal fees and non- financial support from Nordic.

Conflicts of interest for the remaining authors: none.

\section{Funding}

No funding was received to perform this research.

\section{Authors' contributions}


CP-R was the main contributor in the study conception and design. AB and DP-S made substantial contribution to study conception and design. CP-R, AM-F,EO-M and BH-Bcompleted and revised the patient's database. CP-R, DP, AV,LN and IM were involved in obtaining clinical data. AM-F performed the statistical analysis. CP-R and VN-C supervised the statistical analysis. CD actively participated processing the samples and performing the experiments to measure drug and anti-drug antibodies levels. DP-S and PN supervised the drug and anti-drug antibodies levels measurements. AM-F drafted the manuscript. CPR, VN-C, BH-B, DP-S and AB critically reviewed the manuscript. All authors read and approved the final manuscript.

\section{Acknowledgements}

We are grateful to all the rheumatologists and nurses of the Daycare Department for Biologics and to the laboratory technicians of the Immunological Unit .

\section{References}

1. Van Der Heijde D, Ramiro S, Landewé R, Baraliakos X, Van Den Bosch F, Sepriano A, et al. 2016 update of the ASAS-EULAR management recommendations for axial spondyloarthritis. Ann Rheum Dis. 2017;0:1-14.

2. Toussirot É. Biologics in spondyloarthritis: TNFa inhibitors and other agents. Immunotherapy. 2015;7:669-81.

3. Navarro-Compán V, Plasencia-Rodríguez C, de Miguel E, Diaz del Campo P, Balsa A, Gratacós J. Switching biological disease-modifying antirheumatic drugs in patients with axial spondyloarthritis: results from a systematic literature review. RMD Open. 2017;3:e000524.

4. Ducourau $E$, Ternant $D$, Lequerré $T$, Fuzibet $P$, Le Loët $X$, Watier $H$, et al. Towards an individualised target concentration of adalimumab in rheumatoid arthritis. Ann Rheum Dis. 2014;73:1428-9.

5. Pouw MF, Krieckaert CL, Nurmohamed MT, Van Der Kleij D, Aarden L, Rispens T, et al. Key findings towards optimising adalimumab treatment: the concentration-effect curve. Ann Rheum Dis. 2015;74:513-8.

6. Martínez-Feito A, Plasencia-Rodriguez C, Navarro-Compán V, Jurado T, Kneepkens EL, Wolbink GJ, et al. Optimal concentration range of golimumab in patients with axial spondyloarthritis. Clin Exp Rheumatol. 2018;36:110-4.

7. William E, Clair S, Wagner CL, Fasanmade AA, Wang B, Schaible T, et al. The Relationship of Serum Infliximab Concentrations to Clinical Improvement in Rheumatoid Arthritis Results From ATTRACT, a Multicenter, Randomized, Double-Blind, Placebo-Controlled Trial. ARTHRITIS Rheum. 2002;46:14519.

8. Plasencia C, Pascual-Salcedo D, Nuño L, Bonilla G, Villalba A, Peiteado D, et al. Influence of immunogenicity on the efficacy of longterm treatment of spondyloarthritis with infliximab. Ann Rheum Dis. 2012;71:1955-60. 
9. Casteele N, Vande, Khanna R, Levesque BG, Stitt L, Zou GY, Singh S, et al. The relationship between infliximab concentrations, antibodies to infliximab and disease activity in Crohn's disease. Gut. 2015;64:1539-45.

10. Mulleman D, Balsa A. Adalimumab concentration-based tapering strategy: As good as the recommended dosage. Ann Rheum Dis. 2018;77:473-5.

11. Ordás I, Mould DR, Feagan BG, Sandborn WJ. Anti-TNF Monoclonal Antibodies in Inflammatory Bowel Disease: Pharmacokinetics-Based Dosing Paradigms. Clin Pharmacol Ther. 2012;91:635-46.

12. de Vries MK, Wolbink G, Stapel SO. Decreased clinical response to infliximab in ankylosing spondylitis is correlated with anti-infliximab formation. Ann Rheum Dis. 2007;66:1252-4.

13. Charlotte L, Krieckaert MT, Nurmohamed G, Wolbink J. Methotrexate reduces immunogenicity in adalimumab treated rheumatoid arthritis patients in a dose dependent manner. Ann Rheum Dis. 2012;71:1914-5.

14. Vogelzang EH, Pouw MF, Nurmohamed M, Kneepkens EL, Rispens T, Wolbink GJ, et al. Adalimumab trough concentrations in patients with rheumatoid arthritis and psoriatic arthritis treated with concomitant disease-modifying antirheumatic drugs. Ann Rheum Dis. 2015;74:474-5.

15. Hernández-Breijo B, Plasencia-Rodríguez C, Navarro-Compán V, Martínez-Feito A, Jochems A, Kneepkens EL, et al. Association between concomitant csDMARDs and clinical response to TNF inhibitors in overweight patients with axial spondyloarthritis. Arthritis Res Ther. 2019;21:1-7.

16. Teresa J, Chamaida P-R, Ana M-F, Victoria N-C, Theo R, Annick V, et al. Predictive Value of Serum Infliximab Levels at Induction Phase in Rheumatoid Arthritis Patients. Open Rheumatol J. 2017;11:75-87.

17. Kobayashi T, Suzuki Y, Motoya S, Hirai F, Ogata H, Ito H, et al. First trough level of infliximab at week 2 predicts future outcomes of induction therapy in ulcerative colitis-results from a multicenter prospective randomized controlled trial and its post hoc analysis. J Gastroenterol. 2016;51:241-51.

18. 'ami L, Krieckaert MJ, Nurmohamed CL, Van Vollenhoven MT, Rispens RF, Boers T. M, et al. Clinical and epidemiological research Successful reduction of overexposure in patients with rheumatoid arthritis with high serum adalimumab concentrations: an open-label, non-inferiority, randomised clinical trial. Ann Rheum Dis. 2018;77:484-7.

19. Ducourau E, Mulleman D, Paintaud G, Miow Lin DC, Lauféron F, Ternant D, et al. Antibodies toward infliximab are associated with low infliximab concentration at treatment initiation and poor infliximab maintenance in rheumatic diseases. Arthritis Res Ther. 2011;13:R105.

20. Gratacós J, Díaz del Campo Fontecha P, Fernández-Carballido C, Juanola Roura X, Linares Ferrando LF, de Miguel Mendieta E, et al. Recommendations by the Spanish Society of Rheumatology on the Use of Biological Therapies in Axial Spondyloarthritis. Reumatol Clin. 2018;14:320-33.

21. Machado P, Landewé R, Lie E, Kvien TK, Braun J, Baker D, et al. Ankylosing Spondylitis Disease Activity Score (ASDAS): Defining cut-off values for disease activity states and improvement scores. Ann Rheum Dis. 2011;70:47-53. 
22. Pascual-Salcedo D, Plasencia C, Ramiro S, Nuño L, Bonilla G, Nagore D, et al. Influence of immunogenicity on the efficacy of long-term treatment with infliximab in rheumatoid arthritis. Rheumatology. 2011;50:1445-52.

23. Jani M, Chinoy H, Warren RB, Griffiths CEM, Plant D, Fu B, et al. Clinical utility of random anti-tumor necrosis factor drug-level testing and measurement of antidrug antibodies on the long-term treatment response in rheumatoid arthritis. Arthritis Rheumatol. 2015;67:2011-9.

24. Bendtzen K, Geborek P, Svenson M, Larsson L, Kapetanovic MC, Saxne T. Individualized monitoring of drug bioavailability and immunogenicity in rheumatoid arthritis patients treated with the tumor necrosis factor alpha inhibitor infliximab. Arthritis Rheum. 2006;54:3782-9.

25. Van den Bemt BJF, den Broeder AA, Wolbink G, Van den Maas A, Hekster YA, Van Riel PLCM, et al. The combined use of disease activity and infliximab serum trough concentrations for early prediction of (non-) response to infliximab in rheumatoid arthritis. Br J Clin Pharmacol. 2013;76:939-45.

26. Maneiro JR, Souto A, Salgado E, Mera A, Gomez-Reino JJ. Predictors of response to TNF antagonists in patients with ankylosing spondylitis and psoriatic arthritis: Systematic review and meta-analysis. RMD Open. 2015;1:1-11.

27. Sieper J, Landewé R, Magrey M, Anderson JK, Zhong S, Wang X, et al. Predictors of remission in patients with non-radiographic axial spondyloarthritis receiving open-label adalimumab in the ABILITY-3 study. RMD Open. 2019;5:e000917.

28. Visvanathan S, Wagner C, Marini JC, Baker D, Gathany T, Han J, et al. Inflammatory biomarkers, disease activity and spinal disease measures in patients with ankylosing spondylitis after treatment with infliximab. Ann Rheum Dis. 2008;67:511-7.

29. De Vries MK, Van Eijk IC, Van Der Horst-Bruinsma IE, Peters MJL, Nurmohamed MT, Dijkmans BAC, et al. Erythrocyte sedimentation rate, C-reactive protein level, and serum amyloid a protein for patient selection and monitoring of anti-tumor necrosis factor treatment in ankylosing spondylitis. Arthritis Care Res. 2009;61:1484-90.

30. Lorenzin M, Ortolan A, Frallonardo P, Oliviero F, Punzi L, Ramonda R. Predictors of response and drug survival in ankylosing spondylitis patients treated with infliximab. BMC Musculoskelet Disord. 2015;16:10-7.

31. Heinonen AV, Aaltonen KJ, Joensuu JT, Lähteenmäki JP, Pertovaara MI, Romu MK, et al. Effectiveness and drug survival of TNF inhibitors in the treatment of ankylosing spondylitis: A prospective cohort study. J Rheumatol. 2015;42:2339-46.

32. Smolen JS, Schöls M, Braun J, Dougados M, Gerald OF, Gladman DD, et al. Treating axial spondyloarthritis and peripheral spondyloarthritis, especially psoriatic arthritis, to target: 2017 update of recommendations by an international task force. Ann Rheum Dis. 2018;77:3-17.

\section{Figures}


A)

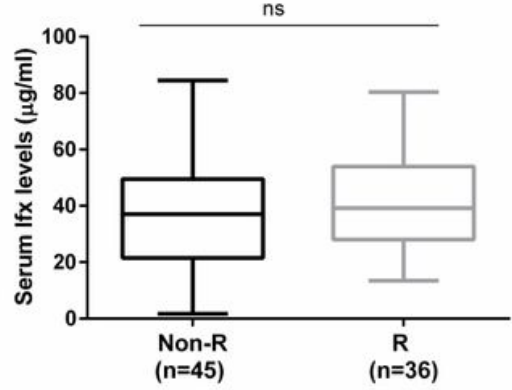

B)

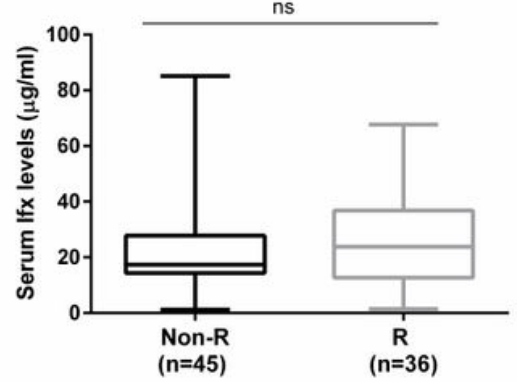

C)

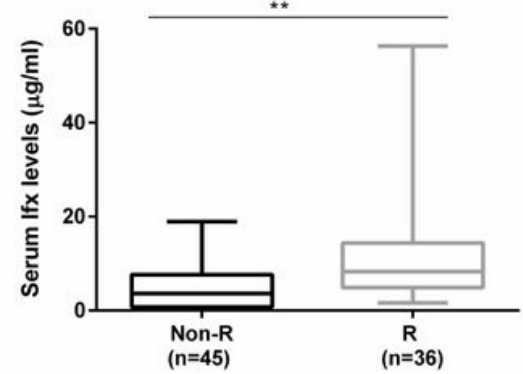

Figure 1

Differences in serum If $x$ trough levels at A)W2, B)W6 and C)W12 according to clinical response ( $\triangle$ ASDAS $<1.1$ and $\triangle A S D A S \geq 1.1)$ at W52. Non-R:Non-responders; R:Responders. ${ }^{*} \mathrm{p}<0.01$

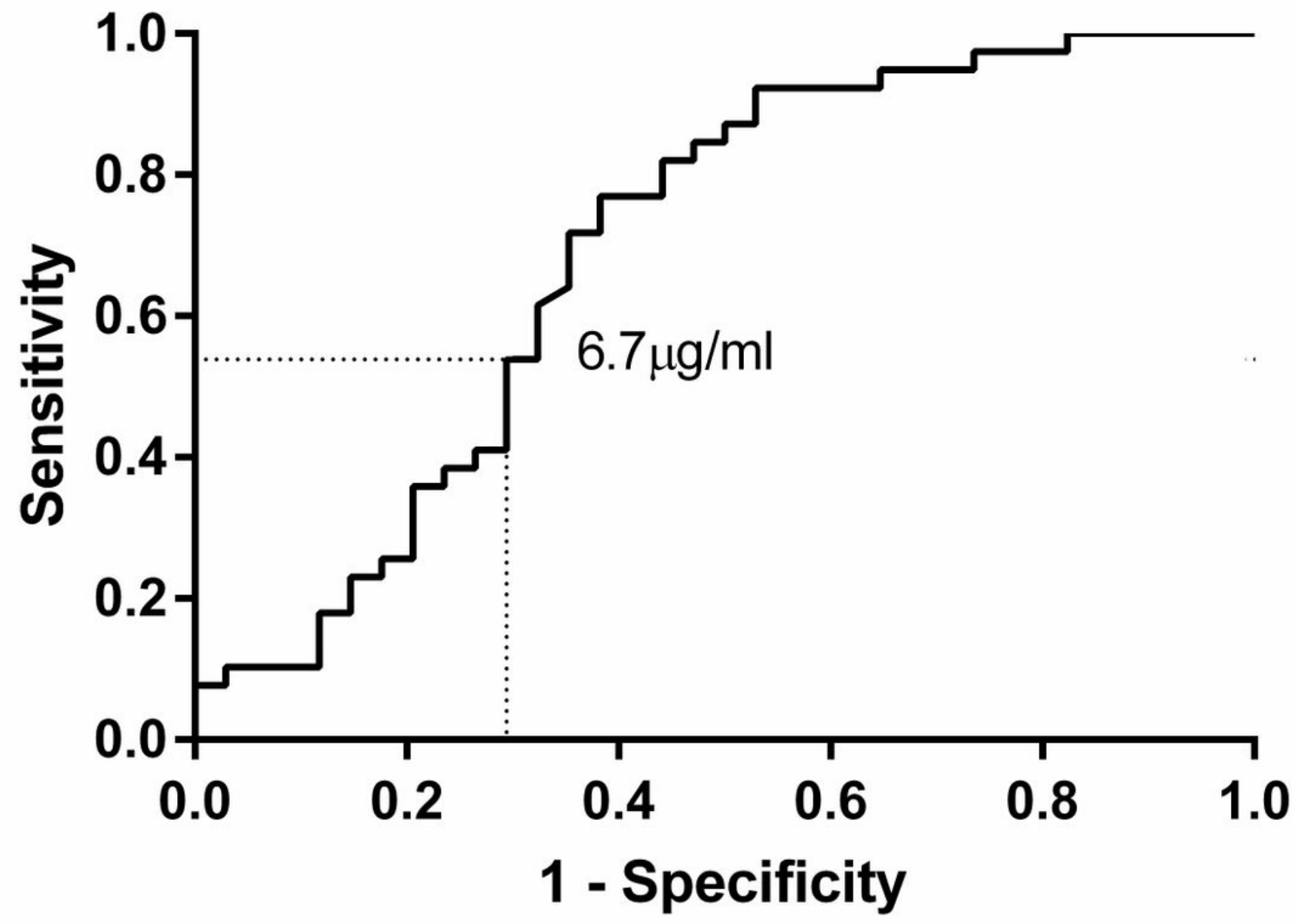

Figure 2 
ROC curve analysis for clinical response as assessed by $\triangle$ ASDAS in relationship to serum trough Ifx levels at W12 (AUC: $0.678, \mathrm{Cl}:(0.558-0.797), p<0.01)$. Discontinuos line shows the cut-off of Ifx concentration at $6.7 \mu \mathrm{g} / \mathrm{ml}$.

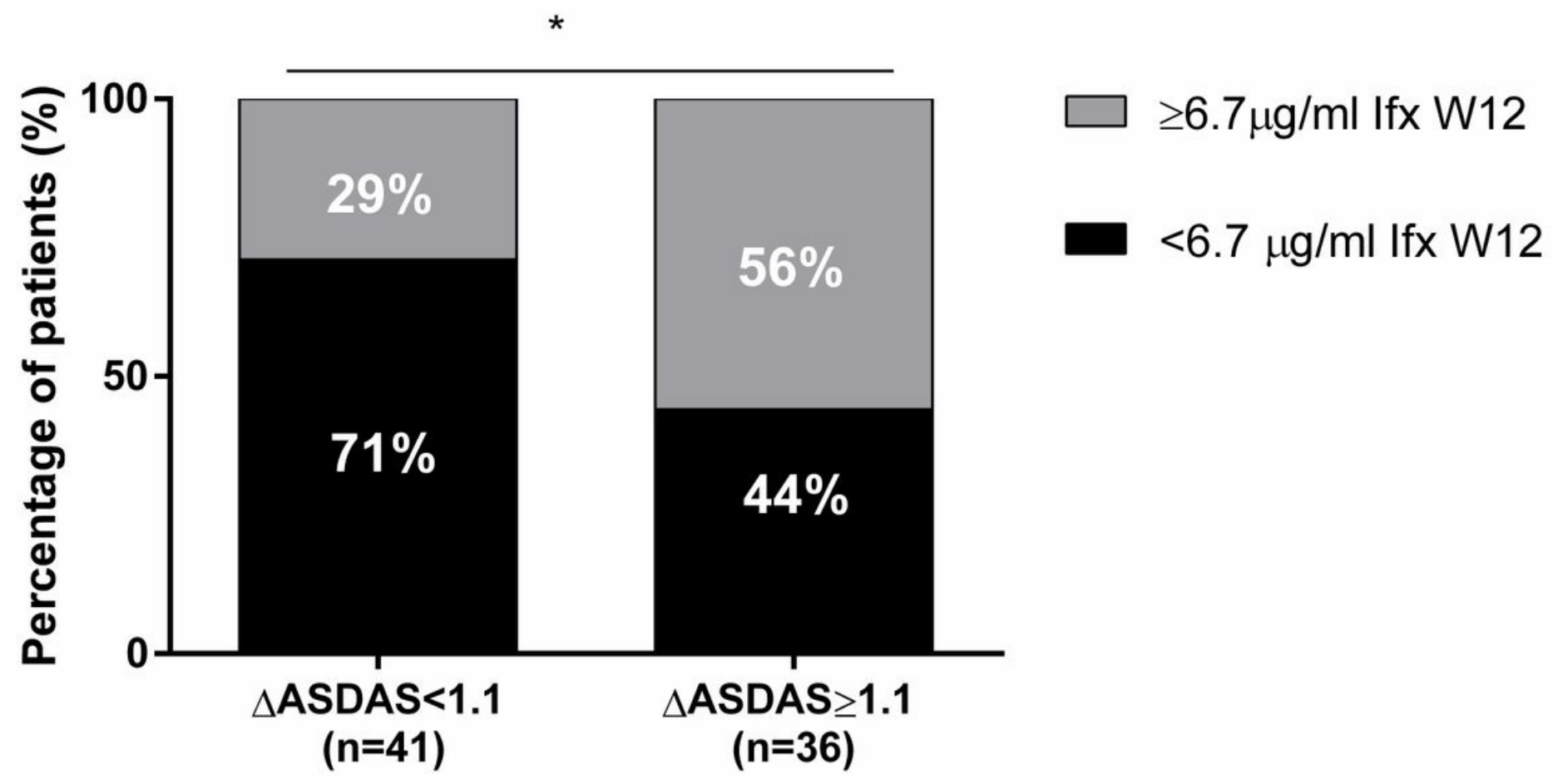

Figure 3

Percentage of patients who achieved clinically important improvement ( $A$ ASDAS $\geq 1.1)$ at W52 according to the cut-off value for serum Ifx levels. ${ }^{\star} p<0.05$.

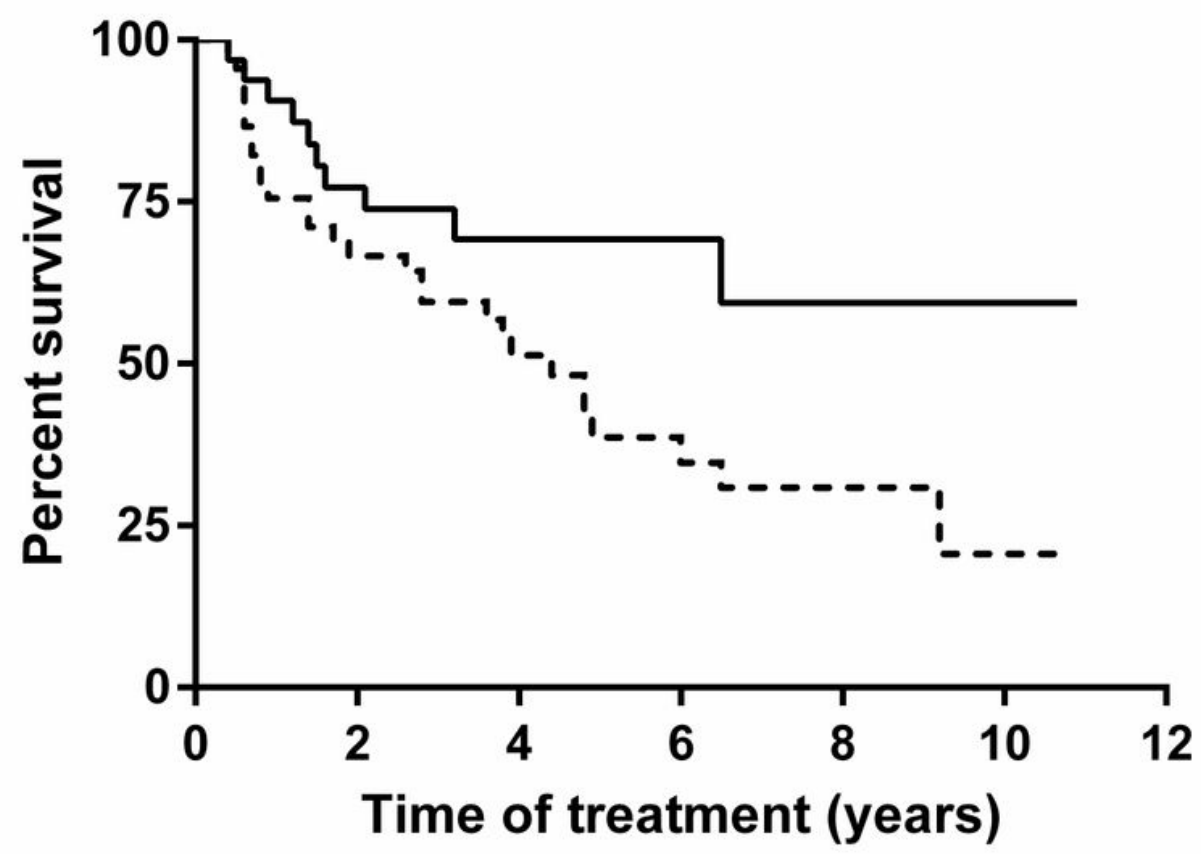

- - $<6.7 \mu \mathrm{g} / \mathrm{ml}$ Ifx W12

— $\geq 6.7 \mu \mathrm{g} / \mathrm{ml}$ Ifx W12 
Figure 4

Drug survival time according to the serum Ifx levels at W12.

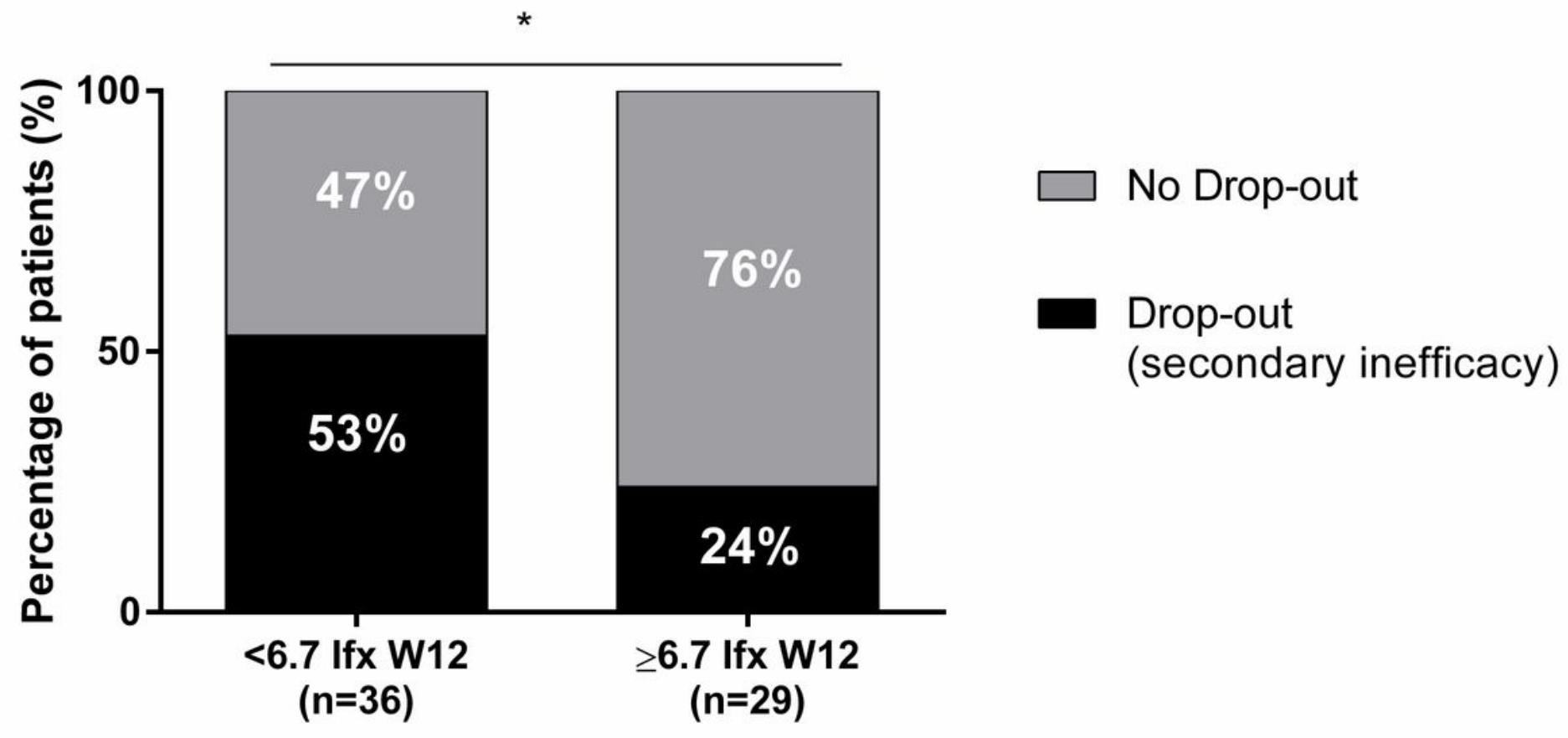

Figure 5

Percentage of patients who dropped-out due to secondary inefficacy according to the cut-off level for Ifx concentration at $\mathrm{W} 12{ }^{*} \mathrm{p}<0.05$.

\section{Supplementary Files}

This is a list of supplementary files associated with this preprint. Click to download.

- renamed1fed4.docx

- renamed1fed4.docx 